\title{
PEDRO PAULO A. FUNARI E A ANFOROLOGIA
}

Haiganuch Sarian ${ }^{1}$

Quando Pedro Paulo me procurou para orientá-lo em suas pesquisas visando a um Mestrado, já tinha ideias muito definidas sobre o tema a ser estudado e, mais do que isso, possuía, ainda muito jovem, bons conhecimentos bibliográficos a respeito: o universo das ânforas romanas e suas implicações econômicas.

Ao longo de uma orientação que me proporcionou enorme satisfação, tal era o empenho do orientando, amadureceram-se os principais elementos sobre uma categoria de ânforas do tipo Dressel 20 (sécs. I-III d.C., particularmente ca.149 d.C.) do nome de Heinrich Dressel, arqueólogo e epigrafista alemão (1845-1920), que desenvolveu uma tipologia para a classificação de ânforas, sendo o Dressel 20 originário da Bética, província da Espanha romana.

Foi assim que com bolsas do CNPq e da FAPESP, entre 1982 e 1985, Pedro Paulo concluiu as suas pesquisas para o Mestrado apresentando a Dissertação intitulada: "As transformações morfológicas das ânforas oleárias béticas do tipo Dressel 20", no Departamento de Antropologia da FFLCHUSP.

As reflexões sobre tal tema levou-o a publicar um estudo que define bem o estatuto dos estudos sobre ânforas:

- A Anforologia: uma nova disciplina arqueológica. Revista de História, São Paulo: FFLCH-USP, v. 118, 1985, p. 161-170.

Como bom ceramólogo, preocupou-se também em buscar a nomenclatura original dos vasos romanos no vocabulário latino e assim publicou dois anos depois o artigo:

1 Professora Titular Sênior, Universidade de São Paulo, São Paulo, Brasil. E-mail: haigasarian@gmail.com 
- Em torno da ânfora. A terminologia latina dos vasos recipientes. In: PINTO, N. F.; BRANDÃO, J. L. (Orgs.). Cultura Clássica em Debate. Anais do I Congresso Nacional de Estudos Clássicos. Belo Horizonte: UFMG/CNPq/SBEC, 1987, p. 51-60, com publicação também em italiano:

- Considerazioni sull'anfora e la terminologia latina dei vasi recipienti. Limes. Santiago do Chile: Universidad Metropolitana de Ciencias de la Educación: Centro de Estudios Clásicos, v. 12, 2000, p. 106-115.

Entre 1986 e 1990, dedicou-se às pesquisas para a sua tese de doutoramento com bolsa da CAPES: defendeu brilhantemente o trabalho "Padrões de consumo do azeite bético na Bretanha Romana", no Departamento de Antropologia da FFLCH-USP. Já se iniciavam as preocupações de Pedro Paulo com o conteúdo das ânforas e a vida econômica, além de estudos tipológicos.

Seguem-se alguns artigos marcantes a partir das reflexões e experiência de Pedro Paulo apresentadas no Mestrado e no Doutorado:

- Estudo tipológico das ânforas oleárias béticas (Dressel 20) de ca. 149 d.C. Dédalo. São Paulo: MAE-USP, v. 25, 1987, p. 209-233 (parte da pesquisa de Mestrado).

- A produção e o consumo de vinho na Antiguidade Clássica. Um balanço dos estudos anfóricos recentes. Revista da Sociedade Brasileira de Pesquisa Histórica. Curitiba: SBPH, v. 7, 1992, p. 77-78.

- Baetica and the Dressel 20 production. An outline of the province's history. Dialogue d'Histoire Ancienne. Besançon: Institut des Sciences et Techniques de l'Antiquité, Université de Franche-Comté, v. 20, n. 1, 1994, p. 87-105.

- Les amphores du Sado, Portugal. Prospection des fours et analyse du matériel. American Journal of Archaeology. Boston: Archaeological Institute of America, v. 102, n. 2, 1998, p. 452-453.

Com toda erudição e maturidade científica, Pedro Paulo nos brinda com a sua tese de Livre-Docência, defendida em 1995 na Universidade Estadual de Campinas (UNICAMP), com o título "As inscrições Dressel 20 provenientes da Bretanha e o consumo do azeite espanhol, com um Catálogo de selos" em 2 volumes. 
Antes de sua tese de Livre-Docência e logo depois de sua defesa, especializou-se o pesquisador em epigrafia latina, particularmente na epigrafia anfórica e, a partir de então, são inúmeras as suas contribuições dentre as quais destacamos:

- Uma inscrição bética inédita dos anos 90 d.C.: observações preliminares. Revista do Departamento de História. Belo Horizonte: Universidade de Minas Gerais, NESP 7, 1988, p. 90-101.

- Dressel 20 amphora inscriptions found at Vindolanda: the Reading of the unpublished evidence. In: MASFIELD, V.A.; DOBSON, M.J. (Eds.). Roman frontier studies 1989. Exeter: University of Exeter Press, 1991, p. 65-72.

- As inscrições béticas inéditas provenientes de Vindolanda. Classica: Revista Brasileira de Estudos Clássicos. São Paulo: Sociedade Brasileira de Estudos Clássicos, v. 5, n. 1, 1993, p. 157-166.

- Some amphora inscriptions from Britain: amphora evidences. Revista do Museu de Arqueologia e Etnologia. São Paulo: MAE-USP, v. 3, 1993, p. 121135.

- Avanços recentes no estudo da Epigrafia Latina das ânforas oleárias béticas. Boletim do CPA. Campinas: UNICAMP/IFCH, v. 7, 1995, p. 363368 .

Se alguns de seus artigos extrapolaram o âmbito nacional é, sem dúvida, a publicação de sua tese de Livre-Docência na Inglaterra, em prestigiosa coleção, que merece os melhores elogios:

- Dressel 20 inscriptions from Britain and the consumption of Spanish olive oil. Oxford: Tempus Reparatum - BAR 250, 1966, 137 p., mapas, ilustrações (Figura 1). 


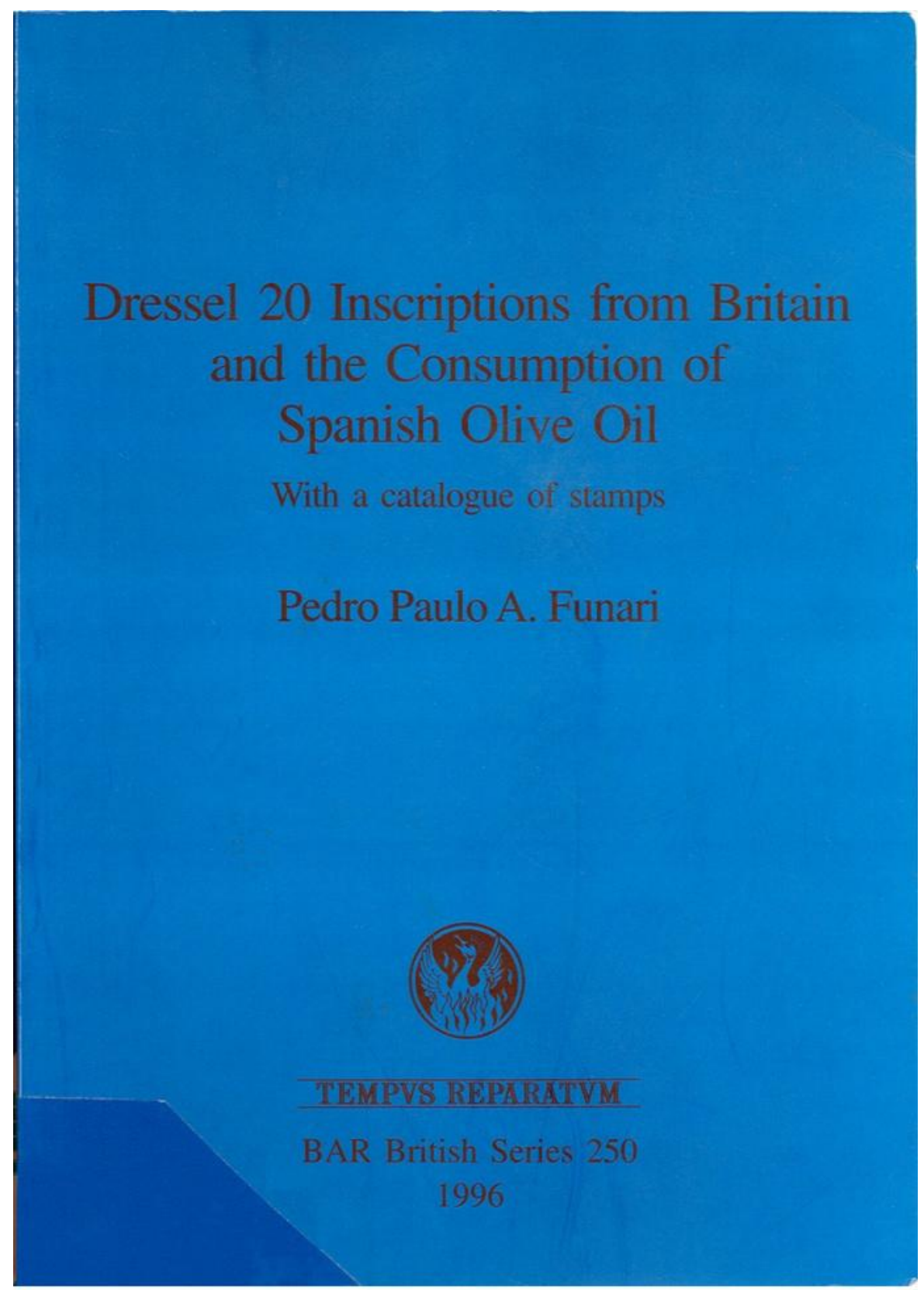

Figura 1. Capa da publicação. Oxford, 1996.

Nesta obra, com grande destaque para a epigrafia das ânforas de tipo Dressel 20 encontradas na Britannia e suas consequências econômicas (comércio do azeite nessa região durante o domínio romano), estabeleceu além da cronologia (séc. III d.C.) o quadro mais completo possível do que se pode inferir da epigrafia anfórica do tipo Dressel 20, a partir de inscrições pintadas, grafites e selos (Figuras 2,3). 


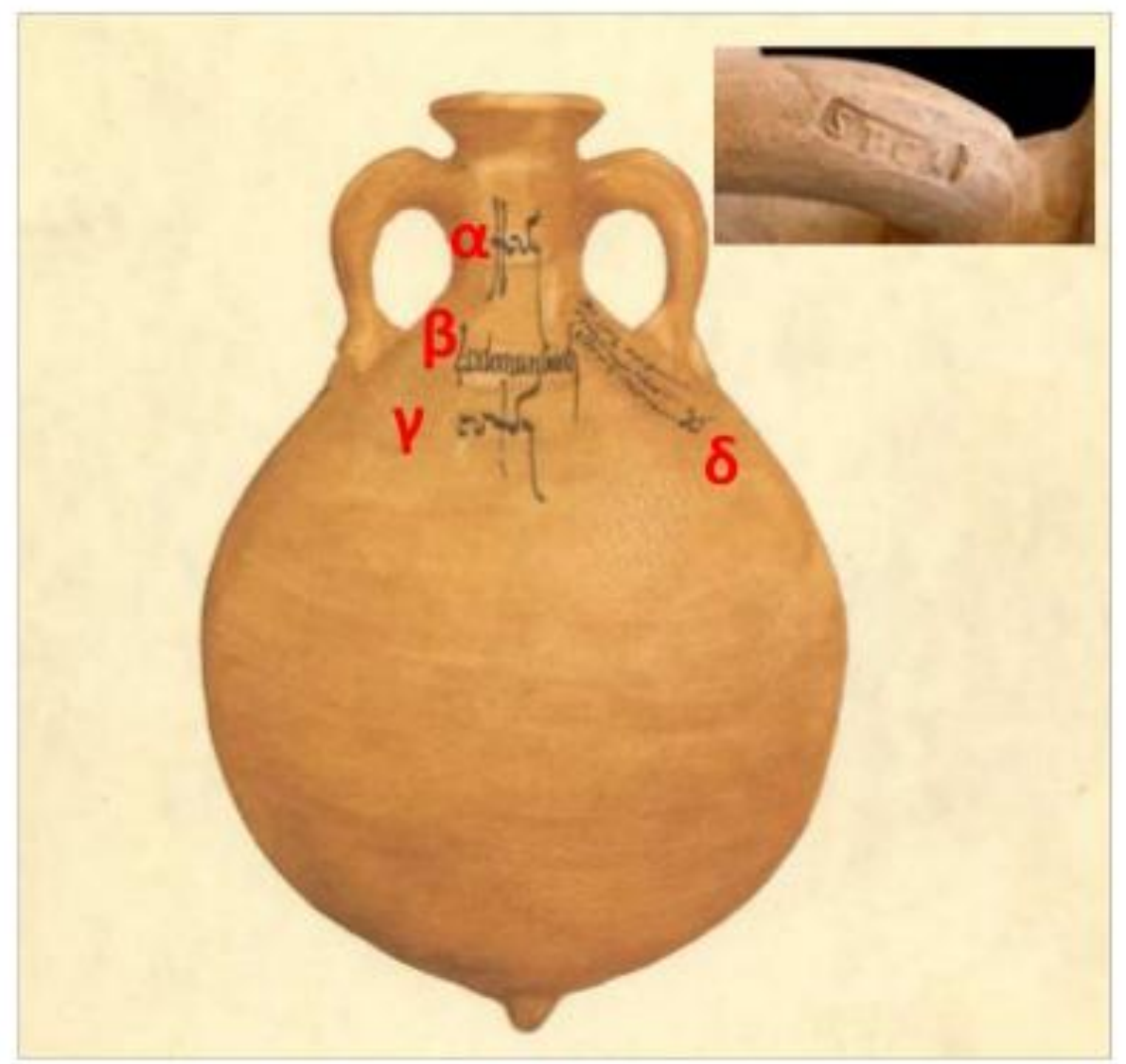

Figura 2. Epigrafia da ânfora Dressel 20; Link: https://goo.gl/images/FYoLSr
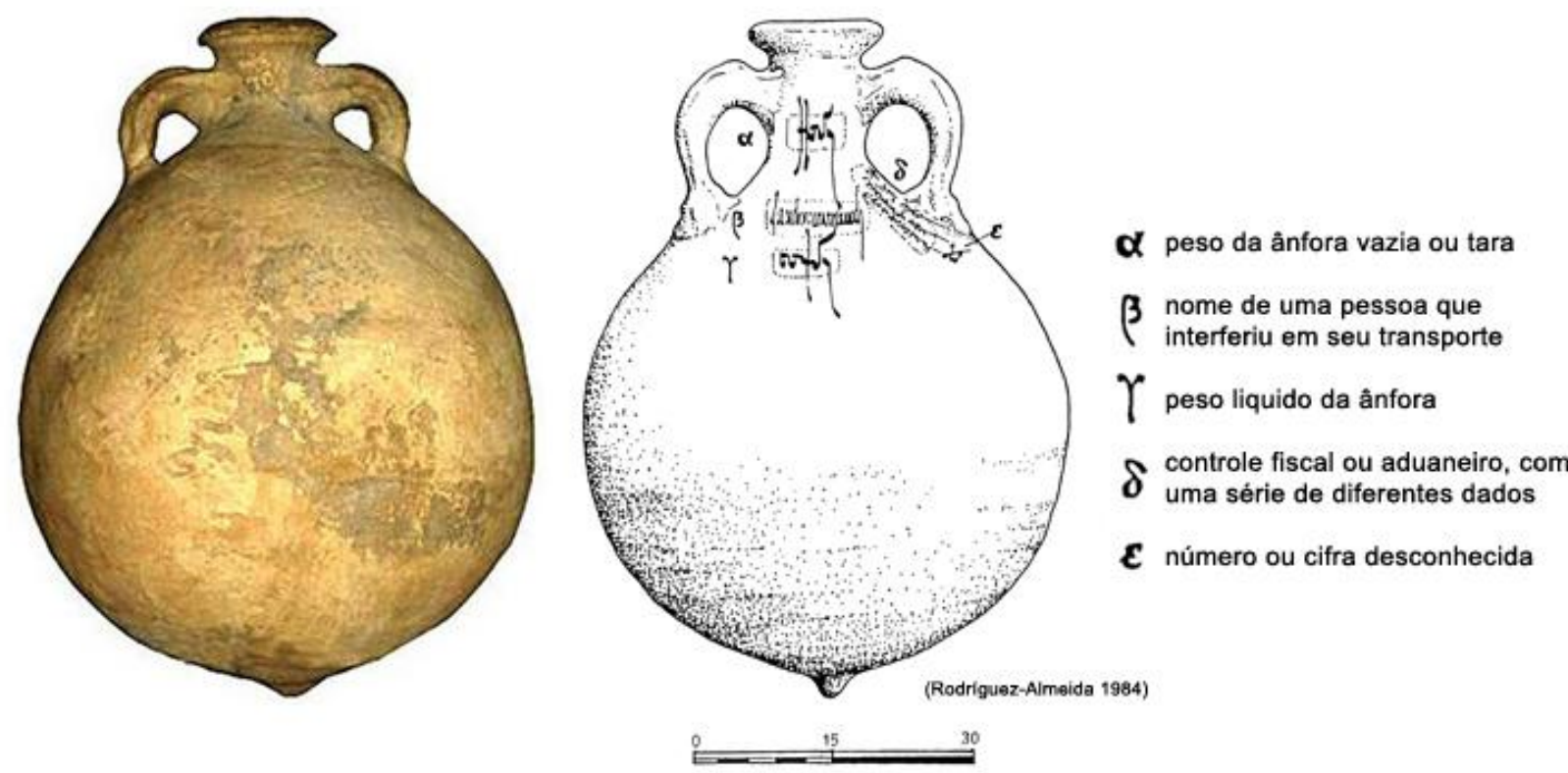

Figura 3. Ânfora Dressel 20 e inscrições. Link: https://goo.gl/images/FyoLSr 
Merece também aplausos a preocupação de Pedro Paulo em publicar ânforas e inscrições anfóricas de coleções de Museus. É assim que publicou ânforas do MASP (Museu de Arte de São Paulo Assis Chateaubriand), do Museu Verulamium (St. Albans, Reino Unido) e do MAE-USP (Museu de Arqueologia e Etnologia, São Paulo). Não foi por falta de seu interesse e de meu empenho que deixou de incluir nessas publicações também as nove ânforas do Museu Nacional (Universidade Federal do Rio de Janeiro).

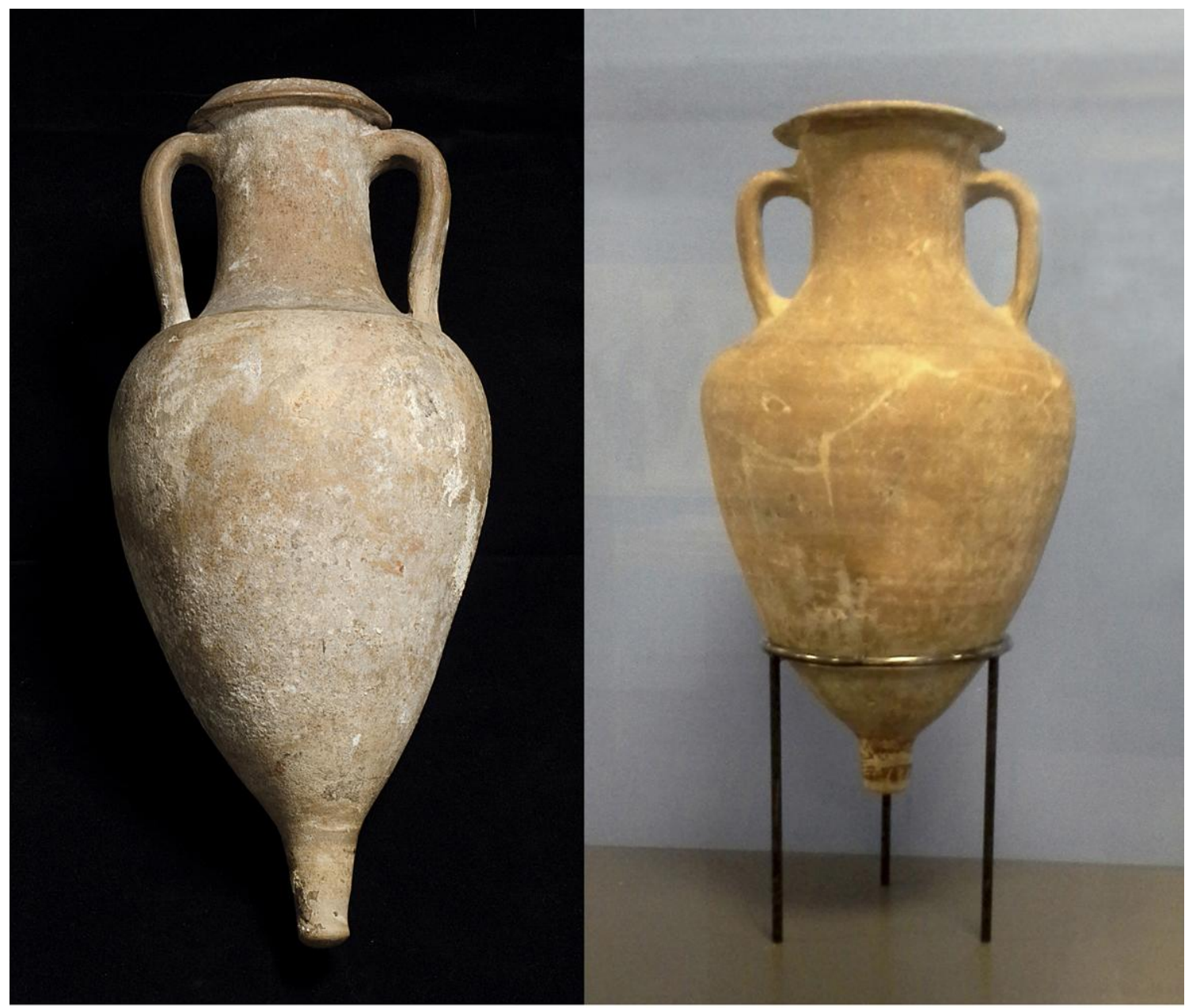

Figura 4. Ânfora greco-itálica. MAE/USP, inv. 64/9.6. Data: 350-250 a.C.. Foto: Ader Gotardo/MAE/USP

Figura 5. Ânfora greco-itálica. MAE/USP, inv. 64/9.5. Data: 350-250 a.C.. Foto: Denise Dal Pino/MAE/USP

- Catálogo de ânfora do MASP. Boletim. Instituto de História da Arte do MASP. São Paulo: MASP, v. 1, 1997, p. 18-20.

- Dressel 20 stamps from the Verulamium Museum. Revista do Museu de Arqueologia e Etnologia. São Paulo: MAE-USP, v. 9, 1999, p. 143-161.

Com esta preocupação em mente, Pedro Paulo foi além das ânforas romanas e da epigrafia latina para dedicar-se à publicação de três ânforas 
anepigráficas (2 greco-itálicas, 1 grega) e de cinco alças de ânforas timbradas com selos em grego (4 de Rodes, 1 de Cnido):

- MAE-USP amphora collection: vessels and inscriptions. Revista do Museu de Arqueologia e Etnologia. São Paulo: MAE-USP, v. 11, 2001, p. 275-282. (Figuras 4, 5, 6).

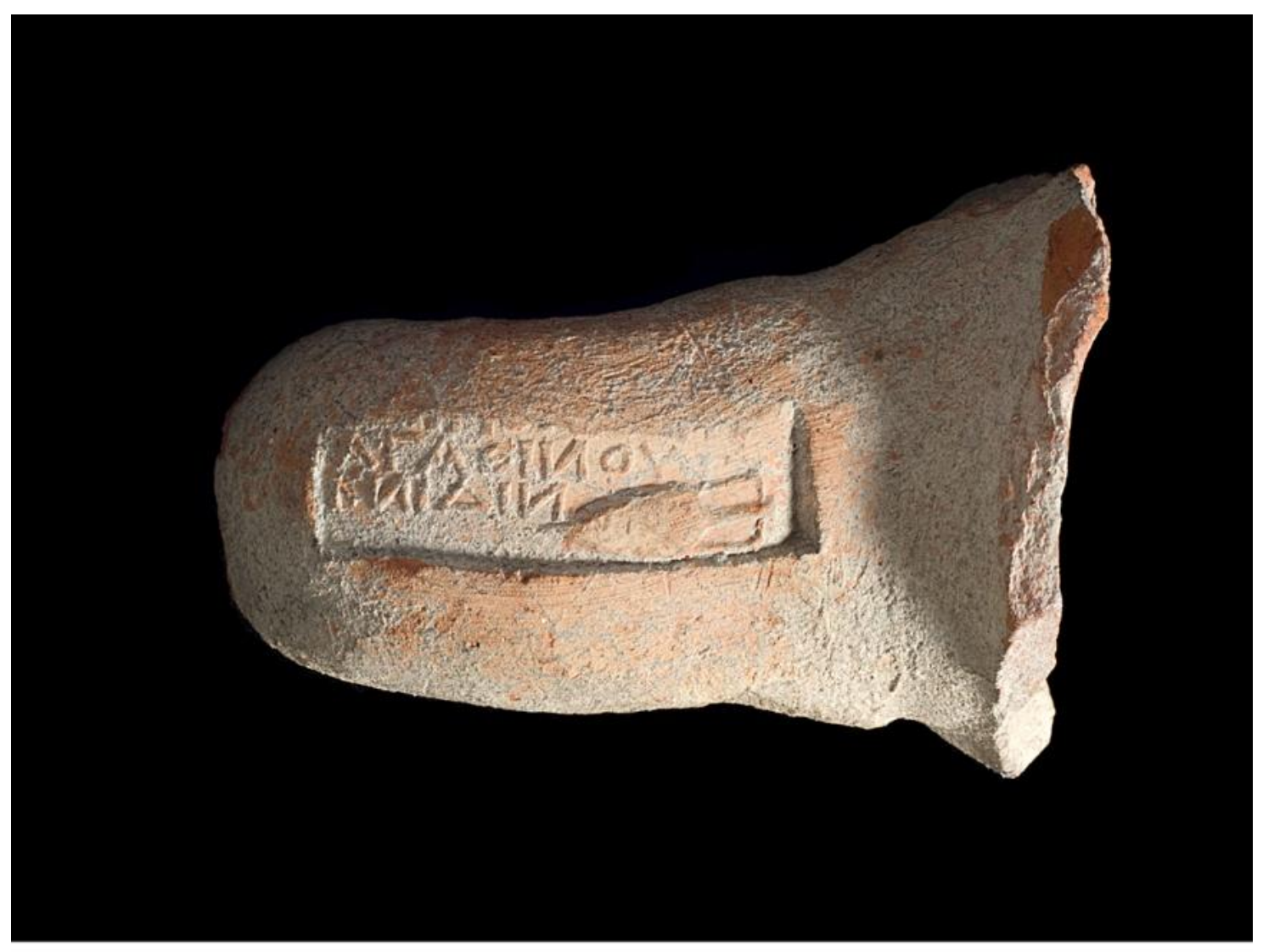

Figura 6. Alça timbrada de ânfora grega (Cnido). MAE-USP, inv. 75/1.43. Data: meados do séc. II a.C.. Foto: Ader Gotardo/MAE/USP

Apenas em 2014 é que Pedro Paulo retomou o tema que lhe foi tão caro por duas décadas publicando o artigo:

- Considerações sobre a contribuição da Arqueologia da Bética para o estudo da economia romana. Revista do Museu de Arqueologia e Etnologia. Suplemento. São Paulo: MAE-USP, n. 18, 2014, p. 19-27.

Neste artigo, mencionando o papel central da Arqueologia para o estudo da economia antiga, estudou o exemplo da Bética e, entre outras evidências de cultura material, salientou os resultados que se podem adquirir através do material anfórico. 
Para finalizar, desejo me referir a parte da narrativa da invenção da escrita feita por Sócrates, na passagem 274c-275d do diálogo Fedro de Platão (428 - 347 a.C.): o inventor da escrita, o deus egípcio Thot, afirmara que a escrita fortaleceria a memória.

Desse modo, eu concluo, se para muitos de nossos colegas, meus e de Pedro Paulo, se apagou a memória de uma fase tão profícua em estudos cerâmicos, permaneceram os escritos que marcaram as primeiras pesquisas e publicações sobre ceramologia clássica no Brasil. Neste sentido, dentre vários alunos que orientei nesta disciplina, Pedro Paulo A. Funari foi um pioneiro exemplar.

\section{Agradecimentos}

Sou grata a Denise Dal Pino (Analista de Comunicação, MAE-USP) pela elaboração das figuras; e a Eleuza Gouveia (ex-Bibliotecária, MAE-USP) por preparar o texto conforme as normas editoriais desta revista. 